\title{
Effect of Naloxone on the Morphine Concentration in the Central Nervous System and Plasma in Rats
}

\author{
Yoshiyuki Miyamoto, Naonori Morita, Nobuo Nakamura, Tetsuji Yamanishi, Shiroh Kishioka and Hiroyuki Yamamoto
}

Department of Pharmacology, Wakayama Medical College, 9-Bancho 27, Wakayama 640, Japan

Received April 5, 1993 Accepted July 15, 1993

\begin{abstract}
We investigated whether the distribution (concentration) of morphine in the central nervous system (CNS) after systemic administration could be an index for the in vivo binding of morphine. Neither the morphine concentration nor its decline correlated with the density of opiate receptors. Naloxone decreased the morphine concentration in some CNS regions and plasma after a high dose of morphine, but not after a small dose of morphine. The CNS regions in which naloxone decreased the morphine concentration did not correlate with the density of opiate receptors, and the concentration ratios (CNS regions versus plasma) of morphine were not affected by naloxone. These results suggested that the morphine concentration in the CNS did not reflect the in vivo binding of morphine and that the naloxone-induced decrease in morphine concentration was not due to a displacement of morphine from its receptor sites but due to a change in morphine kinetics. Pharmacokinetic studies suggested that naloxone decreased the morphine concentration through an increased volume of morphine distribution. This naloxone-induced decrease in morphine concentration may contribute to the naloxone-induced inhibition of morphine action in addition to the competitive antagonism at opiate receptors.
\end{abstract}

Keywords: Morphine, Naloxone, Opiate receptor, Binding (in vivo), Pharmacokinetics

It is well established that adrenalectomy potentiates the antinociceptive action of morphine in rodents $(1,2)$. As its mechanisms, an increase in morphine concentration and an increase in the sensitivity to morphine in the central nervous system (CNS) have been proposed (3-5). It is widely accepted that the distribution (concentration) of some radiolabeled ligands reflect the distribution (density) of their corresponding receptors in in vivo autoradiographic studies. The distribution of radiolabeled opioid ligand has been used as an index of the in vivo binding of opioid (6-8). Therefore if the concentration of morphine in the CNS could be an index of the in vivo binding of morphine, the increased concentration of morphine might reflect an increased affinity or an increased number of opiate receptors in adrenalectomized animals. The purpose of the present study was to investigate whether or not the morphine concentration can be an index of in vivo binding of morphine to its receptors and to investigate the possible participation of opiate receptors in the adrenalectomy-induced increase in morphine concentration. During the study, we found that naloxone decreased the morphine concentration in the CNS and plasma after a large dose of morphine but not after a small dose of morphine.
Thereafter, the effects of naloxone on the plasma kinetics of morphine were studied to address the mechanisms of the naloxone-induced decrease in morphine concentration.

\section{MATERIALS AND METHODS}

Male Sprague Dawley rats (Clea Japan, Tokyo) weighing $240-330 \mathrm{~g}$ were used. They were housed in pairs in hanging wire cages in an air-conditioned $\left(23^{\circ} \mathrm{C}, 60 \% \mathrm{hu}-\right.$ midity) and light-controlled (lights on from 7:00 to 19:00) room. They were allowed free access to food (CA-1, Clea Japan) and water.

\section{Distribution of morphine in the CNS}

Rats were injected s.c. with morphine, $5 \mathrm{mg} / \mathrm{kg}$ (antinociceptive dose) or $20 \mathrm{mg} / \mathrm{kg}$ (cataleptic dose), and sacrificed with sodium pentobarbital $(200 \mathrm{mg} / \mathrm{rat}$, i.p.) at $40 \mathrm{~min}, 120 \mathrm{~min}$ or $360 \mathrm{~min}$ after morphine administration. These times of sacrifice were employed because the distribution of morphine was thought to be already in a state of equilibrium (the time of peak antinociceptive action of morphine was $30 \mathrm{~min}(5))$. In naloxone-treated 
rats, naloxone ( $1 \mathrm{mg} / \mathrm{kg}$, s.c.) was administered $10 \mathrm{~min}$ before, immediately before morphine administration or 20 min before sacrifice. Biological samples were collected as follows: A blood sample was collected by cardio-puncture in a heparinized syringe and centrifuged at $2,000 \times \mathrm{g}$ for $15 \mathrm{~min}$ at $4^{\circ} \mathrm{C}$, and the plasma sample was collected. The brain was dissected by the method of Heffner et al. (9); and the caudate putamen, hypothalamus, pons medulla and cerebellum were collected. The lumbar enlargement of the spinal cord was collected as a spinal cord sample. All biological samples were stored at $-20^{\circ} \mathrm{C}$ until morphine determination. Morphine content was determined by the HPLC-ECD method as previously described (5). The half-life of morphine in the CNS and plasma during 40-120 min was calculated using the individual value of morphine concentration at $120 \mathrm{~min}$ and the mean value of morphine concentration at $40 \mathrm{~min}$. The half-life of morphine during $120-360 \mathrm{~min}$ was calculated in the same manner using the individual data at $360 \mathrm{~min}$ and mean value of $120 \mathrm{~min}$.

\section{Plasma kinetics of morphine}

Rats were implanted with jugular cannulas under anesthesia with sodium pentobarbital ( $50 \mathrm{mg} / \mathrm{kg}$, i.p.) according to Upton (10), and then they were housed individually. They were allowed a recovery period of 4 days after surgery before the pharmacokinetic study. Morphine, $20 \mathrm{mg} / \mathrm{kg}$, was administered i.v. or s.c. $10 \mathrm{~min}$ after a pretreatment with either saline $(2 \mathrm{ml} / \mathrm{kg}$, s.c.) or naloxone $(1 \mathrm{mg} / \mathrm{kg}$, s.c.). Then they were put into $18 \mathrm{~cm} \times 29 \mathrm{~cm}$ $\times 13 \mathrm{~cm}$ (height) cages individually and allowed to more freely throughout the experiment. Blood samples of $0.1-0.2 \mathrm{ml}$ were collected through the jugular cannula at $5,15,30,45,60,90,120,180,240$ and $360 \mathrm{~min}$ after morphine administration. The plasma sample was collected as described above and stored at $-20^{\circ} \mathrm{C}$ until morphine determination. Pharmacokinetic parameters were calculated according to the moment analysis as described by Tanigawara et al. (11). Utilized parameters were as follows: area under the concentration-time curve (AUC), mean residence time (MRT), total clearance (CL), distribution volume at steady state (Vss), mean absorption time (MAT) and bioavailability (F). Parameters for the disposition-kinetics: AUC, MRT, CL ( $\mathrm{CL}=$ dose $/ A U C)$ and Vss $(V s s=M R T \times C L)$ were calculated based on the data of the i.v. experiment. Parameters for the absorption-kinetics: MAT (MAT=individual $\mathrm{MRT}_{\text {s.c. }}$. - mean $\mathrm{MRT}_{\text {i.v. }}$ ) and $\mathrm{F}\left(\mathrm{F}=\right.$ individual $\mathrm{AUC}_{\text {s.c. }} /$ mean $\mathrm{AUC}_{\mathrm{i} . \mathrm{v} .} \times 100, \%$ ) were calculated based on the data of both the i.v. and s.c. experiments.
Drugs

Drugs and their sources were as follows: morphine hydrochloride (Takeda Pharm., Osaka), naloxone hydrochloride (Endo Lab., Garden City, NY, USA) and sodium pentobarbital (Pitman Moore, Indianapolis, IN, USA). The dose and content of morphine were calculated as morphine hydrochloride, and the dose of naloxone was calculated as naloxone hydrochloride. Morphine and naloxone were dissolved in saline $(0.9 \% \mathrm{NaCl})$ and given in a volume of $2 \mathrm{ml} / \mathrm{kg}$.

\section{Statistical analyses}

Comparison of mean values between two groups was performed by the two-tailed Student's $t$-test. Comparison of mean values among more than two groups was evaluated by one way analysis of variance followed by the Newman-Keuls test as described by Tallarida and Murray (12).

\section{RESULTS}

\section{Morphine concentration after s.c. administration of 5} $\mathrm{mg} / \mathrm{kg}$ of morphine

Figure 1 shows the morphine concentration in the CNS and plasma at $40 \mathrm{~min}$ after administration of morphine, $5 \mathrm{mg} / \mathrm{kg}$, s.c. The rank order of morphine concentration was plasma $>$ spinal cord $\geq$ cerebellum $\geq$ hypothalamus $\geq$ caudate putamen $\geq$ pons medulla. Neither naloxone ( 1 $\mathrm{mg} / \mathrm{kg}$, s.c.) administered immediately before morphine nor naloxone administered $20 \mathrm{~min}$ before sacrifice affected the morphine concentrations in the CNS and plasma. Table 1 shows the morphine concentrations in the CNS and plasma at $120 \mathrm{~min}$ and $360 \mathrm{~min}$ after an administration of morphine, $5 \mathrm{mg} / \mathrm{kg}$, s.c. The rank order of morphine concentration was spinal cord $>$ hypothalamus $\geq$ cerebellum $>$ pons medulla $\geq$ caudate putamen $\geq$ plasma at $120 \mathrm{~min}$ after administration; and it was spinal cord $\geq$ medulla pons $\geq$ caudate putamen $>$ hypothalamus $>$ cerebellum $\geq$ plasma at $360 \mathrm{~min}$ after administration. Naloxone $(1 \mathrm{mg} / \mathrm{kg}$, s.c.) administered $20 \mathrm{~min}$ before sacrifice did not affect the morphine concentration at 120 or $360 \mathrm{~min}$ in any CNS region or the plasma. Concentration ratios of morphine (CNS regions versus plasma) were not affected by naloxone (data not shown).

Table 2 shows the half-life of morphine in the CNS and plasma during 40-120 min and during $120-360 \mathrm{~min}$ after morphine administration. During $40-120 \mathrm{~min}$, the halflife of morphine in the plasma was shorter than those in the CNS, but there was no significant difference among the half-lives in the CNS regions. There was no significant difference among the half-lives of morphine during $120-360 \mathrm{~min}$ in the CNS and plasma. 


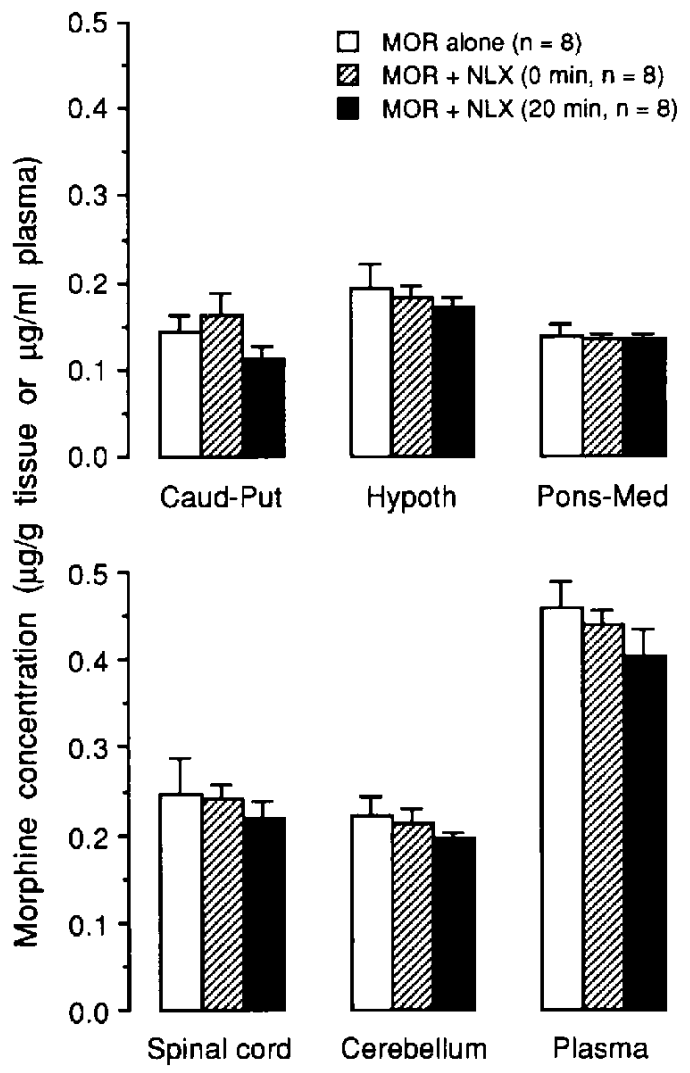

Fig. 1. Effect of naloxone (NLX) on morphine (MOR) concentration in the CNS and plasma at $\mathbf{4 0}$ min after s.c. administration of MOR, $5 \mathrm{mg} / \mathrm{kg}$. NLX, $1 \mathrm{mg} / \mathrm{kg}$, was administered s.c. immediately before MOR administration ( $0 \mathrm{~min}$ ) or $20 \mathrm{~min}$ before sacrifice (20 min). Each column and vertical bar represent the mean and S.E., respectively. Abbreviations: Caud-Put, caudate putamen; Hypoth, hypothalamus; Pons-Med, pons medulla.

\section{Morphine concentration after s.c. administration of 20 $\mathrm{mg} / \mathrm{kg}$ of morphine}

Figure 2 shows the morphine concentration in the CNS and plasma at $40 \mathrm{~min}$ after administration of morphine, $20 \mathrm{mg} / \mathrm{kg}$, s.c. The rank order of morphine concentration was plasma $>$ spinal cord $\geq$ cerebellum $\geq$ hypothalamus $\geq$ pons medulla $\geq$ caudate putamen; and it was similar to that of $40 \mathrm{~min}$ after $5 \mathrm{mg} / \mathrm{kg}$ of morphine. In contrast with the results after $5 \mathrm{mg} / \mathrm{kg}$ of morphine, naloxone (1 $\mathrm{mg} / \mathrm{kg}$, s.c.) administered immediately before morphine significantly decreased the morphine concentration in the caudate putamen, pons medulla, spinal cord and plasma. Similarly, naloxone administered $10 \mathrm{~min}$ before morphine significantly decreased the morphine concentration in the caudate putamen, pons medulla and plasma. On the other hand, naloxone administered $20 \mathrm{~min}$ before sacrifice decreased morphine concentration only in the plasma and it did not affect the morphine concentration in the CNS. Concentration ratios of morphine (CNS regions versus plasma) were not affected by naloxone
Table 1. Effect of naloxone (NLX) on morphine (MOR) concentrations in the CNS and plasma at $120 \mathrm{~min}$ and $360 \mathrm{~min}$ after s.c. administration of MOR, $5 \mathrm{mg} / \mathrm{kg}$

\begin{tabular}{lcc}
\hline & MOR alone & MOR $+\mathrm{NLX}$ \\
\hline 120 min after morphine administration & \\
Caud-Put & $(\mathrm{n}=8)$ & $(\mathrm{n}=7)$ \\
Hypoth & $61.1 \pm 3.6$ & $58.6 \pm 7.6$ \\
Pons-Med & $92.6 \pm 10.0$ & $80.9 \pm 6.6$ \\
Spinal cord & $61.7 \pm 5.3$ & $48.5 \pm 5.0$ \\
Cerebellum & $112.6 \pm 6.1$ & $115.5 \pm 14.9$ \\
Plasma & $87.5 \pm 6.0$ & $80.2 \pm 0.7$ \\
360 min after morphine administration & $54.3 \pm 8.7$ \\
& $(\mathrm{n}=4)$ & \\
Caud-Put & $16.4 \pm 4.1$ & $6.8 \pm 2.5$ \\
Hypoth & $12.9 \pm 2.2$ & $12.5 \pm 1.3$ \\
Pons-Med & $17.9 \pm 2.9$ & $25.6 \pm 3.0$ \\
Spinal cord & $20.2 \pm 2.0$ & $17.4 \pm 2.2$ \\
Cerebellum & $8.8 \pm 0.7$ & $6.4 \pm 1.7$ \\
Plasma & $8.0 \pm 2.5$ & $8.2 \pm 0.7$ \\
\hline
\end{tabular}

Each value represents the mean $\pm S$.E. of the MOR concentration ( $\mathrm{ng} / \mathrm{g}$ tissue or $\mathrm{ng} / \mathrm{ml}$ plasma). MOR concentration was determined $120 \mathrm{~min}$ or $360 \mathrm{~min}$ after MOR administration. NLX, $1 \mathrm{mg} / \mathrm{kg}$, was administered s.c. $20 \mathrm{~min}$ before sacrifice (i.e., $100 \mathrm{~min}$ or $340 \mathrm{~min}$ after morphine administration). For abbreviations, see the legend for Fig. 1 .

Table 2. Half-life of morphine (MOR) in the CNS and plasma after s.c. administration of $5 \mathrm{mg} / \mathrm{kg}$ of MOR

\begin{tabular}{lcc}
\hline & $40-120 \mathrm{~min}$ & $120-360 \mathrm{~min}$ \\
\hline & $(\mathrm{n}=8)$ & $(\mathrm{n}=4)$ \\
Caud-Put & $65.5 \pm 5.1$ & $131.8 \pm 26.9$ \\
Hypoth & $67.3 \pm 5.1$ & $79.8 \pm 4.3$ \\
Pons-Med & $71.4 \pm 7.4$ & $137.2 \pm 17.8$ \\
Spinal cord & $72.3 \pm 5.8$ & $96.9 \pm 5.5$ \\
Cerebellum & $60.7 \pm 4.3$ & $72.4 \pm 2.5$ \\
Plasma & $27.4 \pm 1.4^{*}$ & $82.1 \pm 13.1$ \\
\hline
\end{tabular}

Each value represents the mean \pm S.E. of the half-lives of MOR (min). Values derived from the data of the MOR alone-group in Fig. 1 and Table 1. For abbreviations, see the legend of Fig. 1. *: Value was significantly smaller than those in the CNS regions during $40-120 \min (\mathrm{P}<0.01)$.

(data not shown).

\section{Effect of naloxone on pharmacokinetics of morphine}

Figure 3 shows the time courses of the concentration of plasma morphine after i.v. and s.c. administration of 20 $\mathrm{mg} / \mathrm{kg}$ of morphine. Pretreatment with naloxone (1 $\mathrm{mg} / \mathrm{kg}$, s.c., $10 \mathrm{~min}$ before morphine administration) sig- 


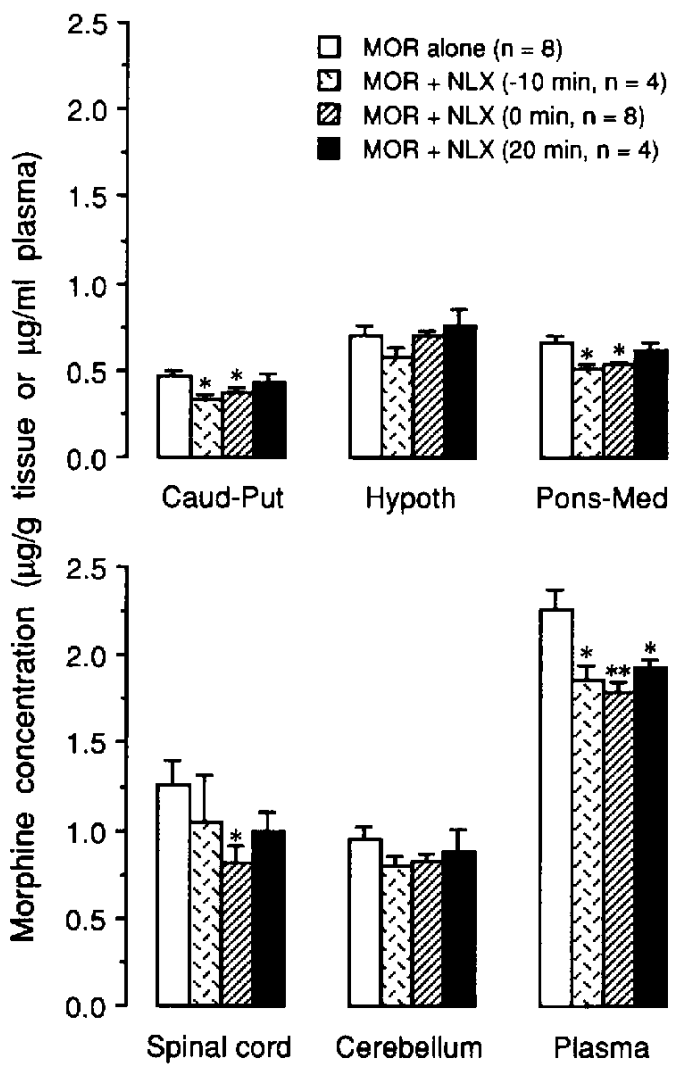

Fig. 2. Effect of naloxone (NLX) on morphine (MOR) concentration in the CNS and plasma at $\mathbf{4 0} \mathrm{min}$ after s.c. administration of MOR, $20 \mathrm{mg} / \mathrm{kg}$. NLX, $1 \mathrm{mg} / \mathrm{kg}$, was administered s.c. $10 \mathrm{~min}$ before MOR administration ( $-10 \mathrm{~min})$, immediately before MOR administration $(0 \mathrm{~min}$ ) or $20 \mathrm{~min}$ before sacrifice $(20 \mathrm{~min})$. Each column and vertical bar represent the mean and S.E., respectively. Significant difference from MOR alone, ${ }^{*} \mathrm{P}<0.05$, ${ }^{* *} \mathrm{P}<0.01$. For abbreviations, see the legend of Fig. 1.

nificantly decreased plasma morphine at 5-180 min after i.v. administration of morphine compared with the saline-pretreated group (Fig. 3, upper frame). Parameters for the disposition-kinetics of morphine are shown in Table 3. Pretreatment with naloxone decreased AUC and increased CL and Vss compared with those of the salinepretreated group. There was no significant effect of naloxone on MRT.

Pretreatment with naloxone $(1 \mathrm{mg} / \mathrm{kg}$, s.c., $10 \mathrm{~min}$ before morphine administration) significantly decreased plasma morphine at 30-180 min after s.c. administration of morphine compared with the saline-pretreated group (Fig. 3, lower frame). The peak times of plasma morphine were $45 \mathrm{~min}$ and $15 \mathrm{~min}$ in the saline-pretreated and naloxone-pretreated rats, respectively. Parameters for the absorption-kinetics of morphine are shown in Table 3. Pretreatment with naloxone decreased MAT and increased $\mathrm{F}$ compared with those of the saline-pretreated group.
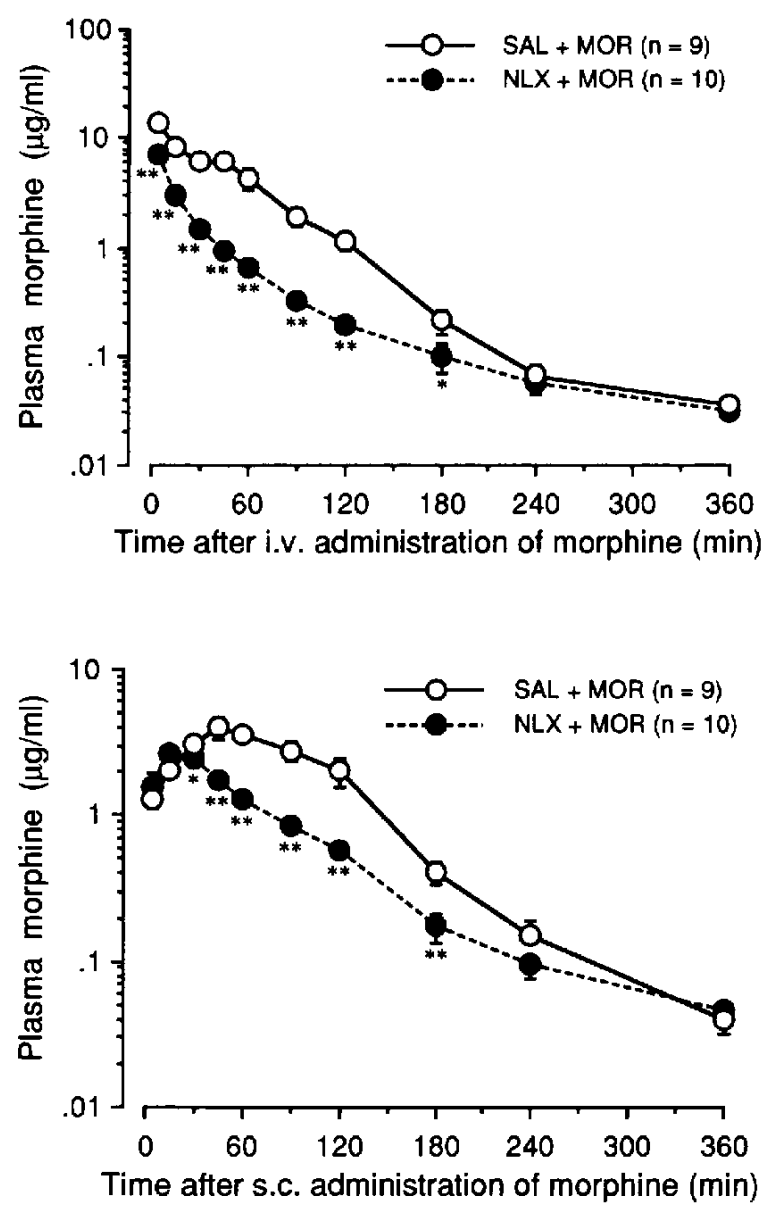

Fig. 3. Effect of naloxone (NLX) on the time courses of morphine (MOR) concentration in plasma after i.v. (upper frame) and s.c. (lower frame) administration of MOR, $20 \mathrm{mg} / \mathrm{kg}$. Each point and vertical bar represent the mean and S.E., respectively. Saline (SAL) or NLX, $1 \mathrm{mg} / \mathrm{kg}$, was administered s.c. $10 \mathrm{~min}$ before MOR administration. Significant difference from $S A L+M O R,{ }^{*} P<0.05$, ${ }^{* *} \mathrm{P}<0.01$.

Table 3. Effects of naloxone on pharmacokinetic parameters of morphine obtained following i.v, and s.c. administration of morphine

\begin{tabular}{lcc}
\hline Parameters & SAL + MOR & NLX +MOR \\
\hline AUC $(\mathrm{hr} \times \mu \mathrm{g} / \mathrm{ml})$ & $10.2 \pm 1.1$ & $2.90 \pm 0.09^{* *}$ \\
MRT $(\mathrm{hr})$ & $0.80 \pm 0.03$ & $0.76 \pm 0.04$ \\
CL $(\mathrm{l} / \mathrm{kg} / \mathrm{hr})$ & $2.16 \pm 0.25$ & $6.96 \pm 0.22^{* *}$ \\
Vss $(\mathrm{l} / \mathrm{kg})$ & $1.67 \pm 0.12$ & $5.26 \pm 0.20^{* *}$ \\
MAT (hr) & $0.58 \pm 0.04$ & $0.43 \pm 0.04^{*}$ \\
F (\%) & $70.8 \pm 8.1$ & $119.0 \pm 7.0^{* *}$ \\
\hline
\end{tabular}

Each value represents the mean \pm S.E. of 9 or 10 rats. Pharmacokinetic parameters were calculated using the data presented in Fig. 3. AUC, MRT, CL and VD are based on the i.v. experiment. MAT and $F$ are based on both the i.v. and s.c. experiments. Significant difference from SAL + MOR, ${ }^{*} \mathrm{P}<0.05,{ }^{* *} \mathrm{P}<0.01$. For abbreviations, see Materials and Methods. 


\section{DISCUSSION}

The rank order of the density of opiate receptors in the rat brain has been reported to be caudate putamen (or striatum) $>$ hypothalamus $\geq$ pons medulla $\gg$ cerebellum $(6,13-15)$. In the present results, the rank order of morphine concentration was plasma $>$ spinal cord $\geq$ cerebellum $\geq$ hypothalamus $\geq$ pons medulla $\geq$ caudate putamen at $40 \mathrm{~min}$ after administration (Figs. 1 and 2), spinal cord $>$ hypothalamus $\geq$ cerebellum $>$ pons medulla $\geq$ caudate putamen $\geq$ plasma at 120 min after administration (Table 1) and spinal cord $\geq$ medulla pons $\geq$ caudate putamen $>$ hypothalamus $>$ cerebellum $\geq$ plasma at 360 min after administration (Table 1). Thus the distribution of morphine did not correlate with the distribution of opiate receptors in the brain at any time investigated in the present study. Especially, the result that the morphine concentration in the cerebellum was higher than those in the other regions in the brain suggested that morphine concentration could not be an index of the in vivo binding. Radiolabeled opioid ligands have been used to investigate the distribution of opioid receptors in the CNS (7, $8,13)$. In those studies, the concentration of radiolabeled ligand in cerebellum was smaller than that in the other areas in the CNS and was utilized as a nonspecific binding. The ligand suitable for an in vivo binding or autoradiographic study must have a high affinity to its target receptors. Thus the difference between the present result and other reports $(7,8,13)$ may be explained by the fact that morphine does not have such a high affinity to opiate receptors $(16,17)$. Next, we examined the possibility that the dissociation of morphine from its receptor sites may be different from that from non-receptor sites and may relate to the density of opiate receptors. If the morphine concentration reflected the in vivo binding of morphine, some difference in the half-life of morphine among the CNS regions would be expected. However, there was no difference in the half-life of morphine among the CNS regions during $40-120 \mathrm{~min}$ or during $120-360 \mathrm{~min}$ after administration. So this result also suggested that morphine concentration could not be an index of in vivo binding.

Naloxone decreased the morphine concentration in some CNS regions after a large dose of morphine but not after a small dose of morphine. A naloxone-induced decrease in morphine concentration in the brain was also reported by Shen and Way (18), and they suggested that the naloxone-induced decrease in morphine concentration reflected a displacement of morphine from its receptor sites. If the decrease in morphine concentration reflects a displacement of morphine from its receptor sites, the decrease should be more apparent after a small dose of morphine than after a large dose of morphine. Ac- cordingly, the present results suggested that the naloxoneinduced decrease in morphine concentration in the CNS was not due to a displacement of morphine from its receptor sites. Moreover, the naloxone-induced decrease in morphine concentration was observed in the caudate putamen, pons medulla, spinal cord and plasma but not in hypothalamus and cerebellum. The CNS regions in which naloxone decreased the morphine concentration did not correlate with the density of opioid receptors. Thus this result supported the above suggestion that the naloxoneinduced decrease in morphine concentration in the CNS was not due to a displacement of morphine from its receptor sites. The concentration ratios of morphine (CNS region versus plasma) were not affected by naloxone. This result suggested that the naloxone-induced decrease in morphine concentration in the CNS was due to a decrease in plasma concentration of morphine. This suggestion was supported by the result that naloxone administered 20 min before sacrifice decreased the morphine concentration in plasma but not in the CNS regions, indicating that the naloxone-induced decrease in morphine concentration initiated in the plasma, and it took some time to affect morphine concentration in the CNS.

Pretreatment with naloxone decreased the plasma concentration of morphine after i.v. and s.c. administration of morphine. Parameters for disposition kinetics obtained following i.v. administration of morphine suggested that naloxone did not affect the elimination of morphine (unchanged MRT), but instead increased the volume of morphine distribution (decreased AUC, increased CL and Vss). Parameters for the absorption kinetics obtained following s.c. administration of morphine suggested that naloxone facilitated the absorption of morphine from the injected site (decreased MAT and increased F). It is well known that opioid agonists (especially in a high dose range) modify cardiovascular functions, and there are several reports that naloxone is useful for treating cardiovascular deficiency $(19,20)$. Naloxone decreased the morphine concentration after a large dose of morphine, but not after a small dose of morphine. This result may suggest that naloxone does not exert its effect in normal cardiovascular function after a small dose of morphine but exerts its effect by reversing the cardiovascular dysfunction which was induced by a large dose of morphine. Naloxone-induced changes in the pharmacokinetic parameters of morphine (facilitated absorption and increased volume of distribution) suggested that morphine inhibited its own absorption and decreased its own volume of distribution. Furthermore, the result that the concentration ratios of morphine (CNS regions versus plasma) were not affected by naloxone suggested that the permeability of morphine through the BBB was left unchanged. 
In conclusion, the present results suggest that the morphine concentration in the CNS does not reflect the density of opioid receptors. The present study also suggested that naloxone reduces morphine concentration after a large dose of morphine through an inhibition of the morphine-induced change of morphine kinetics. The reduced morphine concentration may contribute to the naloxoneinduced inhibition of morphine action in addition to the competitive antagonism at the opioid receptors. Further mechanisms for the naloxone-induced change of morphine kinetics remain to be elucidated.

\section{REFERENCES}

1 Gebhart, G.F. and Mitchell, C.L.: The effect of adrenalectomy on morphine analgesia and tolerance development in rats. Eur. J. Pharmacol. 18, 37-42 (1972)

2 Wei, E.: Morphine analgesia, tolerance and physical dependence in the adrenalectomized rat. Br. J. Pharmacol. 47, 693-699 (1973)

3 Holaday, J.W., Law, P.Y., Loh, H.H. and Li, C.H.: Adrenal steroids indirectly modulate morphine and $\beta$-endorphin effects. J. Pharmacol. Exp. Ther. 208, 176-183 (1979)

4 Ratka, A., Veldhuis, H.D, and De Kloet, E.R.: Corticosteroid effect on morphine-induced antinociception as a function of two types of corticosteroid receptors in brain. Neuropharmacology 27, 15-21 (1988)

5 Miyamoto, Y., Ozaki, M. and Yamamoto, H.: Effect of adrenalectomy on correlation of analgesia with tissue content of morphine. Eur. J. Pharmacol. 167, 11-20 (1989)

6 Pert, C.B. and Snyder, S.H.: Opiate receptor: demonstration in nervous tissue. Science 179, 1011-1014 (1973)

7 Dum, J., Meyer, G., Höllt, V. and Herz, A.: In vivo opiate binding unchanged in tolerant/dependent mice. Eur. J. Pharmacol. 58, 453-460 (1979)

8 Oishi, R., Ozaki, M. and Takemori, A.E.: In vivo binding of naloxone to opioid receptors in morphine-dependent mice. Neuropharmacology 22, 1015-1019 (1983)
9 Heffner, T.G., Hartman, J.A. and Seiden, L.S.: A rapid method for the regional dissection of the rat brain. Pharmacol. Biochem. Behav. 13, 453-456 (1980)

10 Upton, R.A.: Simple and reliable method for serial sampling of blood from rats. J. Pharm. Sci. 64, 112-114 (1975)

11 Tanigawara, Y., Yamaoka, K., Nakagawa, T. and Uno, T.: Moment analysis for the separation of mean in vivo disintegration, dissolution, absorption, and disposition time of ampicillin products. J. Pharm. Sci. 71, 1129-1133 (1982)

12 Tallarida, R.J. and Murray, R.B.: Manual of Pharmacologic Calculations with Computer Programs, 2nd edition, SpringerVerlag, New York (1987)

13 Pert, C.B., Kuhar, M.J. and Snyder, S.H.: Autoradiographic localization of the opiate receptor in rat brain. Life Sci. 16, 1849-1854 (1975)

14 Seeger, T.F., Sforzo, G.A., Pert, C.B. and Pert, A.: In vivo autoradiography: visualization of stress-induced changes in opiate receptor occupancy in the rat brain. Brain Res. 305, 303-311 (1984)

15 Mansour, A. and Watson, S.J.: Anatomical distribution of opioid receptors in mammalians: An overview. In Handbook of Experimental Pharmacology, Vol. 104/I, Opioids I, Edited by Herz, A., pp. 79-105, Springer Verlag, Berlin (1993)

16 Jaffe, J.H. and Martin, W.R.: Opioid analgesics and antagonists. In The Pharmacological Basis of Therapeutics, 8th edition, Edited by Gilman, A.G., Rall, T.W., Nies, A.S. and Taylor, P., pp. 485-521, Pergamon Press, New York (1990)

17 Höllt, V. and Herz, A.: In vivo receptor occupation by opiates and correlation to the pharmacological effects. Fed. Proc. 37, 158- 161 (1978)

18 Shen, J.W. and Way, E.L.: Antagonist displacement of brain morphine during precipitated abstinence. Life Sci. 16, $1829-1830$ (1975)

19 Holaday, J.W.: Cardiovascular effects of endogenous opiate systems. Annu. Rev. Pharmacol. Toxicol. 23, 541 - 594 (1983)

20 Faden, A.I.: Role of endogenous opioids in central cardiovascular regulation and dysregulation. In Handbook of Experimental Pharmacology, Vol. 104/II, Opioids II, Edited by Herz, A., pp. 191-204, Springer Verlag, Berlin (1993) 